2.Ramasamy, I., M. Brisco and A. Morley. 1992. Improved PCR method for detecting monoclonal immunoglobulin heavy chain rearrangement in B-cell neoplasms. J. Clin. Pathol. 45:770-775.

3.Shiach, C.R., P.A.S. Evans, M.A. Short et al. 1993. Detection and accurate sizing of PCR product by automated scanning: improved detection of immunoglobulin gene rearrangement in ALL. Br. J. Haematol. 85:431-433.

4.Wickham, C.L., C. Lynas and S. Ellard. Detection of clonal $\mathrm{T}$ cell populations by high resolution PCR using fluorescently labelled nucleotides; evaluation using conventional LIS-SSCP. J. Clin. Pathol.: Molecular Pathology 53 (In Press).

Received 20 December 1999; accepted 14 April 2000.

The authors would like to thank Mr. M. Boyce, Dr. P. Sarsfield, Dr. R. Lee, Dr. M. Pocock and all members of the Molecular Genetics Laboratory at the Royal Devon and Exeter NHS Healthcare Trust for their support. This work was funded jointly by the Exeter Leukaemia Fund and Amgen UK Ltd. Address correspondence to Caroline Wickham, Molecular Genetics Laboratory, Old Pathology Building, Royal Devon and Exeter NHS Healthcare Trust, Barrack Road, Exeter EX2 5DW, Devon, UK. e-mail: c.l.wickham@exeter.ac.uk

Caroline L. Wickham ${ }^{1,2}$, Miles V. Joyner ${ }^{1}$, Caroline Lynas ${ }^{3}$ and Sian Ellard ${ }^{1,2}$

${ }^{1}$ Royal Devon and Exeter NHS Healthcare Trust

Exeter

${ }^{2}$ University of Exeter

Exeter

${ }^{3}$ Derriford Hospital

Plymouth, UK

\section{Sensitive ELISA for Mouse Erythropoietin}

BioTechniques 29:218-220 (August 2000)

Erythropoietin (Epo), a cytokine produced in fetal liver and adult kidney, stimulates red blood cell production in mammals (2). Treatment with recombinant Epo is beneficial for several forms of anemia, and much effort is currently being devoted to establishing gene therapy protocols to deliver the Epo gene $(3,7)$. To this end, experimentation in rodents is crucial, and a sensitive assay to detect circulating mouse Epo (mEpo) would be useful.

There is strong biological cross-reactivity between mEpo and human Epo (hEpo) connected with the $80 \%$ primary sequence homology between $\mathrm{mEpo}$ and hEpo proteins (8). Despite this high degree of homology, immunological assays that are commonly used to detect hEpo are not sensitive enough to accurately measure basal mEpo levels in mouse plasma and serum $(1,5)$. Recently, an enzyme-linked immunosorbent assay (ELISA), specific for mEpo, was developed by combining specially prepared anti-mEpo with anti-hEpo purified IgGs (4). However, no mEpo ELISA is yet commercially available.

Here, we describe a simple, fast and highly sensitive ELISA for mEpo that makes use of a combination of readymade and commercially available reagents and solutions. These were provided by R\&D Systems (Minneapolis, MN, USA) and Roche Molecular Biochemicals (Mannheim, Germany) and were originally developed for detecting hEpo. The hEpo ELISA kits from these two companies display excellent sensitivity for human Epo but cannot detect mEpo concentrations lower than 20-30 $\mathrm{mU} / \mathrm{mL}$ (Figure 1). Both assays are based on a combination of polyclonal and monoclonal anti-hEpo antibodies. We have tested whether it would be possible to establish a sensitive mEpo ELISA by using a combination of the two different monoclonal antibodies provided by the two kits.

In our ELISA, mEpo is captured on the microtiter plate wells provided in the hEpO ELISA kit from R\&D Systems. These plates are precoated with a murine monoclonal antibody (MAb) against hEpo. For detection, the horseradish peroxidase conjugated mouse MAb anti-hEpo (HRP-anti-hEpo, clone HE 1/5.5.11) provided in the hEpo ELISA kit from Roche Molecular Biochemicals is used. The samples (recombinant mEpo for standard curve or mouse plasma/serum) are diluted with the R\&D specimen diluent. Fifty microliters diluted samples are added to the R\&D microtiter plate wells and incubated at room temperature for $1 \mathrm{~h}$ with continuous shaking. The content is then decanted from each well and 50 $\mu \mathrm{L}$ of the diluted HRP-anti-hEpo MAb from Roche Molecular Biochemicals (dilution: 1:59 with that company's incubation buffer) are added to each well. The plates are incubated for $1 \mathrm{~h}$ at room temperature under continuous agitation; the wells are then washed four times with $200 \mu \mathrm{L}$ R\&D washing buffer. Next, $50 \mu \mathrm{L}$ R\&D substrate solution are added to each well. After 25 min incubation at room temperature, 25 $\mu \mathrm{L}$ R\&D stop solution are added to each well, and the absorbance values are read with a spectrophotometer at $450 \mathrm{~nm}$ (reference wavelength $630 \mathrm{~nm}$ ) within $15 \mathrm{~min}$.

Figure 1 shows a comparison of the standard curves obtained with recombinant mEpo by using either our assay or the hEpo ELISA kits recommended by the two manufacturers. It is evident that combining the monoclonal anti-mEpo antibodies detects mEpo concentrations that are otherwise undetectable by using the two kits separately (Figure 1). The minimum concentration of mEpo that could be quantified with accuracy using our protocol was $1 \mathrm{mU} / \mathrm{mL}$ because the mean plus three standard deviations (SD) of the $0 \mathrm{mU} / \mathrm{mL}$ standard (background value) was lower than the mean -3 SD of the 1-mU/mL sample.

We used this mEpo ELISA to measure mEpo plasma levels in many $\mathrm{Balb} / \mathrm{c}$ mice that were six to eight weeks old. Ten microliters of plasma were used for these measurements. In the majority of mice ( 229 out of 238 , $96.2 \%$ ), plasma mEpo concentration ranged from $1-30 \mathrm{mU} / \mathrm{mL}$ with a mean of $8.5 \pm 4.9 \mathrm{sD} \mathrm{mU} / \mathrm{mL}$. Nine mice (3.8\%) had mEpo values ranging from $31-98 \mathrm{mU} / \mathrm{mL}$ with a mean of $46.7 \pm$ 23.1. Analogous results were obtained in C57/B6 mice. The plasma Epo levels in 27 of 29 mice ranged from 2-20 $\mathrm{mU} / \mathrm{mL}$ with a mean of $7.8 \pm 5.1 \mathrm{sD}$; in two mice, they ranged from 39.8-84.5 $\mathrm{mU} / \mathrm{mL}$ with a mean of $57 \pm 24.1 \mathrm{sD}$.

The precision of the assay was calculated by using the intra-assay coefficient of variations (CV) calculated on the mean Epo values of different samples of the same plasma. These were measured 10 times in the same experi- 
ments. The reproducibility was estimated using interassay $\mathrm{CV}$, calculated on the mean value of several different plasma samples and measured eight times in eight different experiments. Both intra- and interassay cvs were below 9\% (not shown). Finally, the accuracy of the assay was assessed in spiking experiments in which known amounts of recombinant mEpo were added to mouse plasma; between $95 \%$ and $110 \%$ of the added cytokine was recovered. The accuracy was also confirmed by the observation that different dilutions of the same samples constantly gave quite similar results.

We also tested whether this ELISA could be used to detect increases of the mEpo plasma levels following transduction of mice with the mEpo gene. One microgram of plasmid CMV/
mEpo, in which the mEpo cDNA is cloned under the control of the cytomegalovirus (CMV) enhancer/promoter element, was injected into the quadriceps muscle of $30 \mathrm{Balb} / \mathrm{c}$ mice by using the electroinjection technique (5). The mEpo plasma levels measured 14 days after injection ranged from $14.7-52.3 \mathrm{mU} / \mathrm{mL}$ with a mean of 26.6 \pm 9.4 SD. Notably, these plasma levels were significantly higher $(P<0.01$; student's $t$ test) than those detected before injection $(7.9 \pm 3.6 \mathrm{mU} / \mathrm{mL})$.

In conclusion, the ELISA described in this report accurately measures both basal plasma levels of mEpo and the slight increases following intramuscular delivery of small quantities of mEpo expression vectors. Because there are no commercially available ELISAs for mEpo, we believe this assay will be-

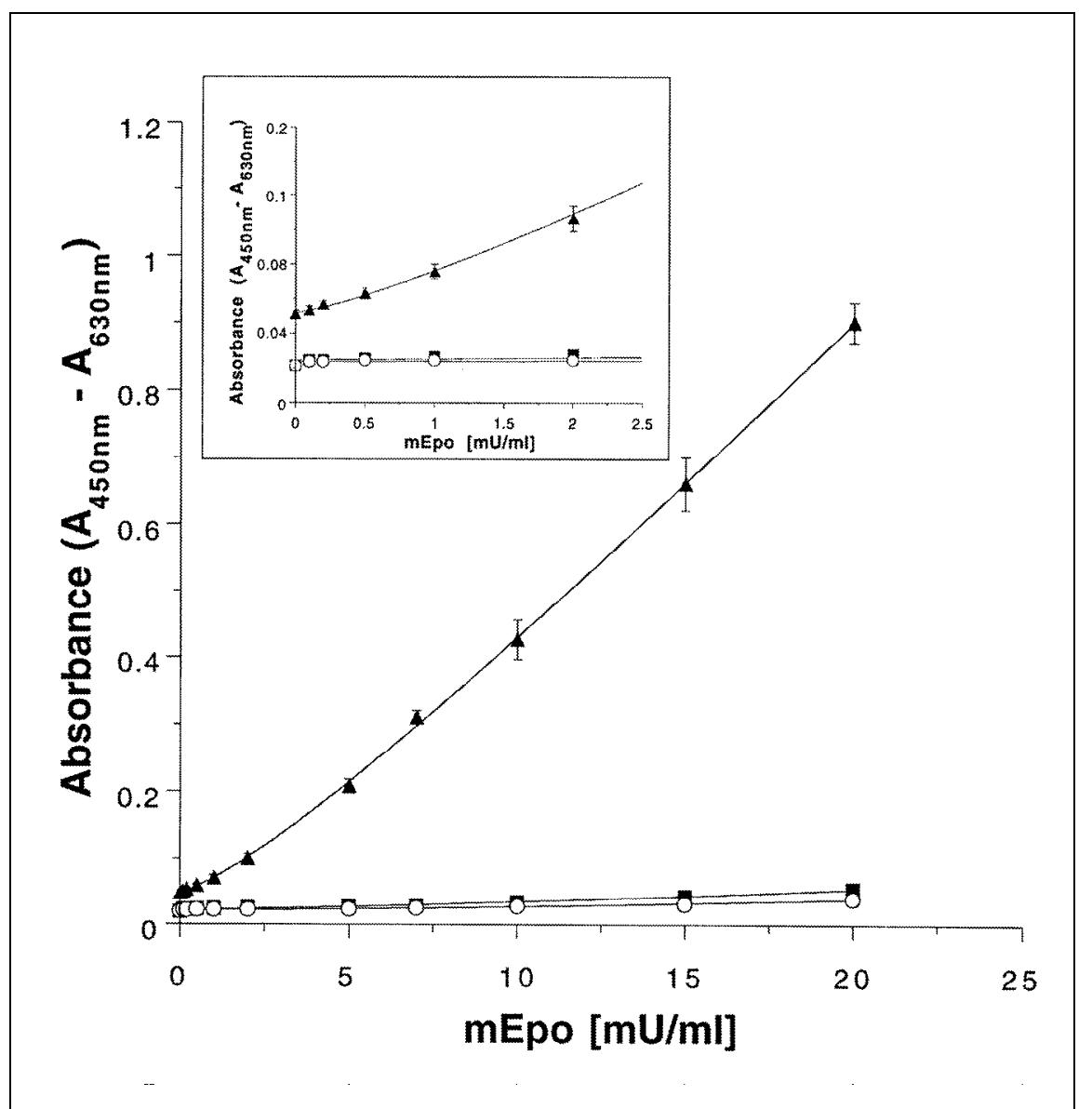

Figure 1. Standard curves with recombinant mEpo. Standard curve with recombinant mEpo (conversion factor: $1 \mathrm{mU}=6.6 \mathrm{pg}$ ) was obtained using the protocol described in the text (filled triangles). The results obtained with the R\&D Systems (filled squares) and Roche Molecular Biochemicals (empty circles) hEpo ELISA kits are shown for comparison. The inset shows a magnification of the $0-2.5 \mathrm{mU}$ $\mathrm{mEpo} / \mathrm{mL}$ region. Data were analyzed by nonlinear regression analysis using the four-parameter logistic model (6). Each point represents the mean of quadruplicate samples; standard deviation is shown.

come an extremely useful tool, especially for those who work in the field of gene therapy.

\section{REFERENCES}

1.Klinman, D.M., J. Conover, J.M. Leiden, A. Rosenberg and J.M.G. Sechler. 1999. Safe and effective regulation of hematocrit by gene gun administration of an erythropoietin-encoding DNA plasmid. Hum. Gene Ther. 8:1891-1900

2.Koury, M.J. and M.C. Bondurant. 1993. The molecular mechanisms of erythropoietin action. Eur. J. Biochem. 210:649-663.

3.Naffakh, N. and O. Danos. 1996. Gene transfer for erythropoiesis enhancement. Mol. Med. Today 8:343-348.

4.Noe, G., W. Riedel, B. Kubanek and I.N. Rich. 1999. An ELISA specific for murine erythropoietin. Br. J. Haematol. 104:838-840.

5.Rizzuto, G., M. Cappelletti, D. Maione, R. Savino, D. Lazzaro, P. Costa, I. Mathiesen, R. Cortese et al. 1999. Efficient and regulated erythropoietin production by naked DNA injection and muscle electroporation. Proc. Natl. Acad. Sci. USA 96:6417-6422.

6.Rodbard, D. and G.R. Frazier. 1975. Statistical analysis of radioligand assay data. Methods Enzymol. 37:3-22.

7.Spivack, J.L. 1993. Recombinant erythropoietin. Ann. Rev. Med. 44:243-253.

8.Wen, D., J.-P.R. Boissel, T.E. Tracy, R.H. Gruninger, L.S. Mulcahy, J. Czelusniak, M. Goodman and H.F. Bunn. 1993. Erythropoietin structure-function relationships: high degree of sequence homology among mammals. Blood 82:1507-1516.

We thank Stefania Lamartina and Giuseppe Roscilli for useful discussions. We also thank Janet Clench for editing the manuscript. Address correspondence to Dr. Carlo Toniatti, Istituto di Ricerche di Biologia Molecolare, I.R.B.M.-P. Angeletti, Via Pontina Km 30,600, 00040, Pomezia (Rome), Italy.e-mail: toniatti@irbm.it

Received 3 February 2000; accepted 27 March 2000.

\section{Daniela Rinaudo and \\ Carlo Toniatti \\ Istituto di Ricerche di Biologia Molecolare Pomezia (Rome), Italy}

